\title{
Beyond Gun Control: Examining Neoliberalism, Pro-gun Politics and Gun Violence in the United States
}

\author{
Luigi Esposito $^{1}$ and Laura L. Finley ${ }^{2}$
}

\begin{abstract}
Although the tragic shooting at Sandy Hook Elementary in Newtown, Connecticut prompted national debate about how to minimize gun violence, these exchanges have tended to focus almost exclusively on issues related to gun control. Our central point in this article is that these discussions have largely ignored the relevance of neoliberalism in terms of how this market ideology has, particularly since the 1980s, supported many of the values, perspectives, and behaviors that are central to America's pro-gun culture and politics. We discuss how neoliberal ideology bolsters problematic pro-gun claims related to: (1) the dangers of "big government," (2) the virtues of "rugged individualism" and self-reliance, and (3) gun violence as a personal problem involving evil, sick, or irresponsible individuals. We also address how the sort of hyper-masculine subject associated with pro-gun politics is compatible with (and reinforced by) the sorts of values and forms of agency encouraged within a neoliberal market society. We conclude by making the point that efforts to minimize gun violence must move beyond the issue of gun control and focus on challenging the neoliberal ideological forces and social structures that, among other things, erode social bonds, encourage hyper-individualism, and normalize a survival of the fittest ethic. [Article copies available for a fee from The Transformative Studies Institute. E-mail address: journal@transformativestudies.org Website: http://www.transformativestudies.org (C2014 by The Transformative Studies Institute. All rights reserved.]
\end{abstract}

KEYWORDS: Neoliberalism, Gun Politics, American Gun Culture, Gun Violence, Gun Control, Masculinity.

\footnotetext{
${ }^{1}$ Luigi Esposito, Ph.D., is Associate Professor of Sociology and Criminology at Barry University in Miami Shores, FL. He has published numerous articles and chapters on issues related to race and ethnic relations, social theory, globalization, and ethics. His research has appeared in various professional journals, including The Sociological Quarterly, The Western Journal of Black Studies, Humanity and Society, Journal of Aging and Identity, Studies in Symbolic Interaction, and Perspectives on Global Development and Technology. He is co-editor (with Vicente Berdayes and John W. Murphy) of the book The Body in Human Inquiry: Interdisciplinary Explorations of Embodiment. (Cresskill, NJ: Hampton Press. 2004); and is also co-editor (with Laura Finley) of the book Grading the 44th President: A Report Card on Barack Obama's First Term as a Progressive Leader (Santa Barbara, CA; Praeger/ABC-CLIO). Address correspondence to: Luigi Esposito, Barry University, 11300 NE Second Avenue, Miami Shores, FL 33161; e-mail: lesposito@mail.barry.edu.

${ }^{2}$ Laura Finley, Ph.D. is Assistant professor of Sociology and Criminology at Barry University in Miami Shores, FL. She has published several books and numerous articles on a variety of social issues. Dr. Finley also is also a community activist, serving with several non-profits to provide services to victims of domestic violence and essential human rights. Her current work is focused on peace education in colleges and universities.
} 